\title{
Un capítulo olvidado de la tecnología y la ciencia mexicanas: Luis Gutiérrez Villegas y la poliomielitis en México
}

Antonio Velázquez-Arellano

Unidad de Genética de la Nutrición del Instituto de Investigaciones Biomédicas, Universidad Nacional Autónoma de México y del Instituto Nacional de Pediatría, Ciudad de México, México

\section{Resumen}

Dos diferentes tipos de vacunas se desarrollaron contra la poliomielitis: la de virus inactivado de Salk y la de virus vivo con virulencia atenuada, de Sabin, que tuvo que esperar a estudios subsecuentes para garantizar su inocuidad. En 1957, nuestro país elaboró la primera con sus propios medios gracias a jóvenes investigadores y técnicos, coordinados por el Dr. Luis Gutiérrez Villegas, investigador, patólogo clínico, profesor universitario y presidente de la Academia Nacional de Medicina.

PALABRAS CLAVE: Poliomielitis. Vacuna. Salk.

\begin{abstract}
Two different types of vaccines were developed against poliomyelitis: The Salk vaccine using inactivated virus and the Sabin one, that was used later, after investigations assured its safety. The first one was made in Mexico with its own resources since 1957 thanks to the efforts of young researchers and technicians coordinated by Luis Gutiérrez-Villegas, M.D., who was a Clinical Pathologist, University Professor and President of the Mexican National Academy of Mexico.
\end{abstract}

KEY WORDS: Poliomyelitis. Vaccine. Salk. 


\section{El flagelo de la poliomielitis, el presidente F.D. Roosevelt y la «Marcha de los dieces»}

En la primera mitad del siglo pasado azotaban al mundo epidemias de poliomielitis, que alcanzaron muy grandes proporciones en los veranos, que dejaban a innumerables niños incapacitados, paralíticos, y que causaban la muerte de muchos otros ${ }^{1}$. Eran nuevas las epidemias veraniegas, mas no la enfermedad, de la que se tienen registros históricos cuando menos desde tiempos de los antiguos egipcios ${ }^{2}$. El presidente Franklin D. Roosevelt padeció esta enfermedad y sufrió serias secuelas; de aquí el gran apoyo que dio a su atención con la Fundación Nacional contra la Parálisis Infantil y su programa March of Dimes, que obtuvo cuantiosos fondos para apoyar investigaciones cuyo objetivo fuese evitar este mal mediante una vacuna que resultase eficaz y segura. Paralelamente al recrudecimiento de los brotes epidémicos de la poliomielitis, hubo avances muy importantes en el conocimiento del virus. Muchas de las mejores mentes científicas de países avanzados estaban dedicadas fervientemente a encontrar la forma de acabar con este flagelo que azotaba a la niñez mundial, y también a muchos adultos. Culminando estos esfuerzos, en 1955 se demostró que la vacuna desarrollada por el científico norteamericano Jonas Salk era segura y eficaz.

\section{Una epopeya mexicana}

A mediados del siglo pasado, México era un país con una incipiente infraestructura científica, con un número pequeño de investigadores, prácticamente ninguno ocupado a tiempo completo, y cuyo gasto en ciencia y tecnología era casi inexistente. Sin embargo, en 1957, México, que poco figuraba dentro de la comunidad científica internacional, logró la proeza de ser el segundo país del mundo, después de Canadá, en fabricar, exclusivamente con sus propios medios, la vacuna Salk, y de empezar a vacunar a cientos de miles de niños mexicanos, que pronto se convertirían en millones ${ }^{3}$. El resultado fueron decenas de miles de niños salvados de la discapacidad y de la muerte.

En la siguiente crónica describiré algunos de los esfuerzos que permitieron este logro, producto de un notable conjunto de personas, y me referiré en particular a quien realizó la labor principal de planeación, coordinación y promoción: el Dr. Luis Gutiérrez Villegas (LGV).

\section{Luis Gutiérrez Villegas}

Realizó sus estudios profesionales en la Escuela Nacional de Medicina entre 1918 y 1924. Se interesó por la medicina experimental y por las contribuciones de disciplinas científicas al diagnóstico médico. Como maestro, fue formador de las primeras generaciones de patólogos clínicos. En 1943 fundó los laboratorios clínicos del Hospital Infantil de México ${ }^{4}$, que serían el modelo del apoyo científico al diagnóstico en este hospital y en las otras nuevas instituciones creadas en esa época. En 1952 fue presidente de la Academia Nacional de Medicina de México ${ }^{5}$.

A lo largo de toda su vida realizó trabajos de investigación de variada índole, interesándose en especial en los virus y rickettsias y en las enfermedades ocasionadas por ellos ${ }^{6}$. Realizó principalmente contribuciones a los conocimientos sobre la oncocercosis, la tuberculosis, el mal del pinto, la brucelosis y la poliomielitis; varias de sus investigaciones las realizó junto con los doctores Galo Soberón y Parra y Gerardo Varela. Publicó muchos de sus trabajos en Gaceta Médica de México, órgano de la Academia Nacional de Medicina.

\section{Dos instituciones fundamentales con las que México enfrentó la poliomielitis y unos jóvenes héroes científicos}

A fines de la década de 1940 recrudecieron las devastadoras epidemias de poliomielitis. La trayectoria de LGV, sucintamente descrita antes, sus aportes a la investigación médica, sus dotes de organizador y la estimación y aprecio que se le tenía en las esferas científica, médica, gubernamental y empresarial, hacían de él un líder idóneo para enfrentar esta epidemia. En el combate que se libró en México contra el flagelo de la poliomielitis, en la década de 1950, fundó y dirigió dos instituciones que tuvieron una importancia crucial en la lucha contra la poliomielitis en México: el Centro de Estudios sobre la Poliomielitis y la División de Investigación Biológica de la Industria Nacional Químico-Farmacéutica (INQF). El primero fue un organismo de consultoría del que surgieron las políticas y recomendaciones para trazar las rutas para el tratamiento, la rehabilitación y la investigación de la «polio», y financiamientos de diversos proyectos sobre la enfermedad. Su patronato estuvo integrado por Antonio Carrillo Flores, Octaviano Longoria, Rafael Mancera, Carlos Novoa, Aarón Sáenz, Carlos Trouyet y Salvador Zubirán, todos ellos notables 
médicos, estadistas, banqueros y empresarios de la época. Por su parte, la INQF fue una organización gubernamental que englobaba las distintas empresas alemanas incautadas por el gobierno mexicano cuando nuestro país entró en guerra con las potencias del Eje. Entre ellas se encontraban La Viga, fábrica de productos químicos; Beick Felix-Stein-México, Guadalajara y Mazatlán, Casa Bayer; General de Anilinas; Insecticidas; Laboratorios Codex; Laboratorios Farquenal; Merck-Knoll-Shering; Casa Lammers; y en especial para los fines del presente trabajo, el Instituto Behring7. El primer director de la INQF fue el Dr. Salvador Zubirán. El Instituto Behring estaba dedicado a la fabricación de «antisueros», y Salvador Zubirán se empeñó en que LGV lo dirigiese, dada su experiencia previa en el Instituto de Higiene. Este último aceptó la invitación en 1953, a cambio de la creación de un centro de investigación biomédica moderno, con plazas de tiempo completo para brillantes investigadores jóvenes. Fue así como en 1954 surgió la División de Investigación Biológica (DIB) de la INQF, en los propios terrenos del Instituto Behring, en las calles Arenal y Tecoyotitla, a unos pasos del parque y monumento a Álvaro Obregón, en el sur de la Ciudad de México.

Si aún hoy este proyecto suena ambicioso, haberlo ideado cuando se iniciaba la década de 1950 en México constituía una verdadera utopía que a todas luces parecía imposible de realizar. Pero nunca una idea noble y trascendente le pareció imposible a Salvador Zubirán; la propuesta de LGV le entusiasmó y le brindó todo su apoyo, un impulso político importante y visión hacia el futuro de México.

La DIB fue un hito en las ciencias médicas de México, desgraciadamente olvidado casi por completo en la actualidad, con investigadores jóvenes de vanguardia, remunerados adecuadamente para dedicarse a tiempo completo a labores científicas de su elección, aunque teniendo como «telón de fondo» la poliomielitis. Así fueron contratados Carlos Campillo Sainz, José Sosa Martínez, Enrique Cifuentes y Raquel Martínez Gracia para virología; Efraín Pardo Codina para farmacología; José Laguna García para bioquímica; y algunos más jóvenes como Raúl Ondarza, Victoria Chagoya y Guadalupe Villaseñor, entre otros. Todos ellos serían, en poco tiempo, los forjadores de las nuevas generaciones de científicos biomédicos. Sin embargo, al principio ninguno de ellos se imaginaba la hazaña que les correspondería realizar. Este ambicioso proyecto requería una visión científica, gran capacidad de organización y liderazgo, conjunción de libertad con responsabilidad, respeto y confianza aunados a supervisión, y una excelente administración de los recursos financieros limitados; LGV reunía estas cualidades.

Con el tiempo, Salvador Zubirán regresó a dirigir su amado Hospital de Nutrición (el actual Instituto Nacional de Ciencias Médicas y Nutrición Salvador Zubirán), y tomó el relevo de la INQF otro gigante de la medicina nacional, Gustavo Baz, a quien correspondió poner en operación a la DIB en 1954 (Fig. 1). En la introducción a una recopilación, en 1955, de 18 trabajos científicos no publicada formalmente, que comunicaron las primeras investigaciones de la DIB, LGV se refirió a «la necesidad de hacer labor de investigación en los campos de la bioquímica, de la farmacología y de la microbiología, sobre problemas de interés científico fundamental, así como de fomentar el estudio de las posibilidades de aplicación que puedan tener dichas investigaciones, en beneficio del país».

\section{Dos estrategias diferentes $y$ un enfrentamiento sin piedad}

Al principio, la lucha contra la «polio» tuvo como único recurso la gammaglobulina hiperinmune contra los virus de la «polio», que se preparó y utilizó en México desde $1952^{8,9}$. Por el momento era la única línea de defensa, aunque poco eficaz, contra la epidemia. El arma decisiva necesariamente tendría que ser una vacuna segura y eficaz. Las dificultades para lograrla eran enormes, pues se ignoraba casi todo sobre la biología del virus, y los intentos previos, en las décadas de 1930 y 1940, no solo habían sido rotundos fracasos, sino que las pretendidas vacunas habían ocasionado la invalidez y la muerte de muchos niños ${ }^{1}$. Los intentos habían sido empíricos, de ensayo y error, por lo que el ambiente era de franco pesimismo y escepticismo.

Sin embargo, el estudio de las bacterias y de los virus estaba en el centro de la atención de una de las revoluciones más formidables en la historia de la ciencia, que conduciría a la actual biología molecular ${ }^{10}$. Se habían dado también avances importantes en el cultivo de células de mamíferos, entre ellas las humanas, y en 1949 se descubrió que existen tres variedades inmunológicamente diferentes del virus de la poliomielitis $^{11}$, con inmunogenicidad y virulencia variables, y con antígenos distintos, lo que permitía diferenciarlas en el laboratorio con facilidad. Ese mismo año, en el Children's Hospital de Boston, el Dr. John Enders y 


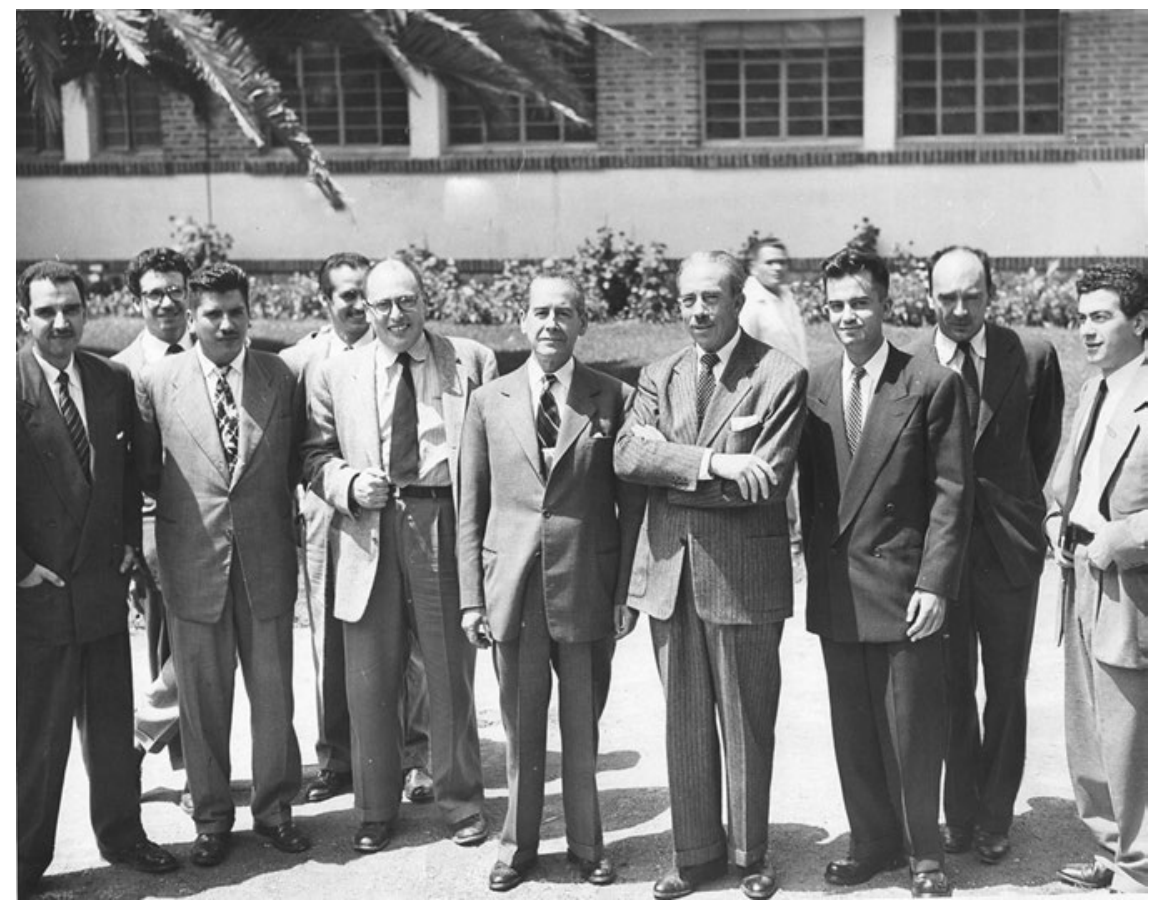

Figura 1. Frente a la División de Investigación Biológica, en las posiciones 3-8: doctores Efraín Pardo, Luis Gutiérrez Villegas, Gustavo Baz, C.P. Oscar Philibert, José Laguna y Juan Urrusti.

sus colaboradores, Fred Robbins y Tom Weller, lograron la proeza de cultivar una de las variedades del virus en células de riñón de monos Rhesus ${ }^{12}$, lo cual abrió las posibilidades de poder entender mucho mejor al virus, amén de que les valió recibir el Premio Nobel en 1954 (junto con, entre otros, Ernest Hemingway y Linus Pauling). Con estos y otros conocimientos, Jonas Salk, en la Universidad de Pittsburgh, inició sus investigaciones, cuya meta era obtener una vacuna confiable contra la poliomielitis ${ }^{13}$.

Desde la primera vacuna, de Jenner, contra la viruela, todas habían sido con virus con virulencia atenuada, incapaces de provocar la enfermedad, sino, cuando mucho, algunas molestias menores como fiebre o dolor de cabeza, pero que conservaban su inmunogenicidad, o sea, su capacidad de mantener esa información en la memoria inmunitaria para que, en el futuro, al ser invadido por el patógeno, el sistema inmunitario reaccionase produciendo la respuesta inmunitaria (anticuerpos) que lo defendería y prevendría la enfermedad. Así fue, por ejemplo, la famosa vacuna contra la rabia que desarrolló Luis Pasteur.

Pero para la segunda mitad de la década de 1940, muchos de los enigmas sobre la naturaleza de los virus empezaban a disiparse. Los experimentos pioneros de Oswald Avery y sus colegas en el Instituto Rockefeller, en Nueva York, indicaban claramente que el material genético de las bacterias, y por extensión de todos los seres vivos, incluyendo los virus, radicaba en sus ácidos nucleicos, el ADN, mientras que su inmunogenicidad dependía de sus proteínas ${ }^{14}$. Fue así como Salk decidió diseñar una vacuna a base de un virus cuyo ADN fuese inactivado con formaldehído, como lo venía haciendo en sus intentos previos por lograr una vacuna contra la influenza. En 1951 demostró su eficacia en monos; en 1952, casi en secreto, empezó la inoculación de seres humanos ${ }^{13}$. Por otro lado estaba Albert Sabin, quien desde hacía casi dos décadas venía realizando notables investigaciones sobre el virus de la poliomielitis, y que proponía una vacuna más tradicional, de virus vivo «atenuado», esto es, como se explicó más arriba, que su virulencia hubiese sido atenuada al punto de no producir enfermedad clínica, pero que hubiese conservado su antigenicidad, su capacidad de despertar una respuesta inmunitaria suficientemente potente para evitar la enfermedad cuando el niño se infectase con virus silvestres virulentos ${ }^{15}$. Estaban así echadas las bases para una contienda que sería larga, fiera y amarga.

En las obras de divulgación científica, los investigadores son seres casi angelicales, que de forma desinteresada y usualmente con gran humildad dedican por entero su vida al bien de la humanidad. La realidad es decepcionantemente distinta a esta idílica visión de biografías de científicos para niños, que en 
mucho se asemejan a las vidas de los santos. Quienes nos dedicamos a la ciencia somos seres humanos como cualquier otro y tenemos todas las sombras y las luces de la naturaleza humana, todas sus grandezas y sus debilidades. "La ciencia es una carrera, una competencia furiosa, en la cual los individuos combaten para ser el primero, ya que sin la prioridad, el descubrimiento es una fruta amarga ${ }^{16}$.

\section{«El mayor experimento de salud pública jamás realizado»}

Tanto porque su diseño estaba más adelantado, como por razones de seguridad, la vacuna Salk fue la primera que se puso a prueba en 1954, mediante uno de los estudios epidemiológicos más amplios y cuidadosos que se hubiesen llevado a cabo hasta entonces $^{17}$. El director de esta investigación epidemiológica fue el Dr. Thomas Francis, director de la prestigiada Escuela de Salud Pública de la Universidad de Michigan, en Ann Arbor, en los EE.UU., y antiguo maestro de Salk. La evaluación sobre la seguridad y la efectividad de la vacuna se hicieron por el procedimiento denominado «doble ciego»: un grupo de niños eran vacunados mientras que otro, que servía como control, recibía solo un placebo, pero ni los pacientes y sus padres, ni los médicos y las enfermeras que les administraban la sustancia experimental, conocían la identidad de la vacuna o del placebo, que estaba oculta mediante unas claves que se encontraban a buen resguardo. Una vez efectuada la investigación clínica, Francis y sus colaboradores realizaron los complejos estudios estadísticos en absoluto secreto mientras no hubiera un resultado claro y contundente. Fue el 24 de abril de 1955, en el Auditorio Rackham, de la Escuela de Posgrado de la Universidad de Michigan, abarrotado de periodistas, cuando el Dr. Francis dio el veredicto: «la vacuna contra la poliomielitis puesta a prueba es segura, eficaz y potente ${ }^{18}$. La noticia se esparció rápidamente por el mundo; ya nada iba a ser igual, en los veranos, para millones de niños que antes tenían un alto riesgo de quedar inválidos o de fallecer.

Albert Sabin, en Cincinnati, logró tiempo después desarrollar un diferente tipo de vacuna contra la poliomielitis a base de virus "vivos» (capaces de reproducirse), inmunogénicos también, pero reducida grandemente su virulencia ${ }^{19}$, con el riesgo siempre presente de mutaciones que devolviesen a algunos (muy pocos) virus su virulencia. De hecho, este riesgo es imposible de impedir y sus consecuencias han sido que algunos (también muy pocos) niños que reciben la vacuna Sabin desarrollan la enfermedad, quedando paralíticos o muriendo. Pero tenía una ventaja logística: se podía administrar por la boca, mientras que la de Salk requería ser inyectada. En el caso de la vacuna Salk, dado que utiliza un virus con su material genético inactivado, el factor seguridad solo está ligado a aspectos de control de calidad. Sabin nunca aceptó que se emplease la vacuna diseñada por Salk, a quien consideraba un amateur en el campo de la poliomielitis, y se había opuesto de manera tenaz, pero infructífera, a los estudios de Salk y a la prueba de su vacuna financiados por la Fundación Nacional contra la Poliomielitis - March of Dimes.

Lo que ocurrió entre los dos científicos fue verdaderamente un duelo de gigantes, un duelo entre dos concepciones distintas de las técnicas de inmunización, entre dos conceptos de vacunas y entre dos maneras de ver los virus (recuérdese que en esos tiempos estaba naciendo lo que ahora llamamos biología molecular) ${ }^{1}$. Pero el conflicto era también entre dos fuertes personalidades, muy distintas entre sí, y entre las inmensas ambiciones y envidias mutuas entre ellos. Salk representaba, en cierta forma, una nueva forma de hacer biomedicina, sustentada en los nuevos y todavía debatidos conceptos sobre el papel de los ácidos nucleicos y las proteínas en la esencia de los seres vivos. Sabin era muy diferente: un hombre con carisma, además de inteligente, muy astuto, a quien se le daban con facilidad las relaciones públicas y que, en el ámbito científico, representaba la ortodoxia, de modo que sus colegas lo veían como uno de los suyos. Pero lo que igualaba a Salk y a Sabin fue que ambos eran guerreros formidables, con ambiciones sin límite e implacables en sus deseos de predominar sobre el contrario.

Salk había ganado claramente, pero como se vio poco tiempo después, apenas la primera batalla, importantísima sin duda alguna, pero al fin solo una batalla de una guerra. Sabin de ninguna manera se consideraba derrotado, y estaba confiado en que con el tiempo ganaría la partida decisiva. Y no estaba dispuesto a esperar demasiado tiempo; en plan de guerrero, no veía tan serio el problema de la seguridad de la vacuna con virus vivos atenuados.

\section{Una victoria pírrica}

La veleidosa fortuna, que había sonreído a Salk y lo había convertido en un gran héroe, súbitamente le volvió la espalda. Tres grandes laboratorios 
farmacéuticos de los EE.UU. habían sido elegidos para fabricar los millones de dosis de vacuna Salk con que se inmunizaría a todos los niños norteamericanos en el menor tiempo posible. Uno de ellos, Ios Laboratorios Cutter, tuvieron una seria brecha en el control de calidad de la producción de la vacuna: en varios lotes, el virus no fue inactivado en forma completa ${ }^{20}$ y así, a miles de pequeños, al ser vacunados se les aplicó virus vivo, de alta virulencia, y desarrollaron la enfermedad, quedando paralíticos o muriendo muchos de ellos. La tragedia colmó los titulares de las primeras planas de todos los periódicos del mundo y fue un serio revés para la confianza que se tenía en la vacuna Salk, que sus detractores no iban a desaprovechar. La competencia entre los dos tipos de vacuna había dejado de ser científica y se había convertido en una guerra política sin cuartel.

La tragedia provocada por el error de los Laboratorios Cutter fue como un regalo de municiones para los enemigos de la vacuna Salk, y les permitió pasar de la defensiva a la ofensiva. Hasta ese momento, el argumento principal para detener el uso de la vacuna Sabin, de fácil administración oral, había sido el de la seguridad; para emplearla había que tener paciencia y prudencia, y esperar varios años de complejas pruebas epidemiológicas, pues es más fácil demostrar algo que existe que algo que está ausente, en este caso, la ausencia o un grado muy bajo de reversibilidad de los efectos patogénicos de los virus vivos atenuados. La vacuna Salk, se argumentaba con pasión, aunque con todas sus limitantes y problemas logísticos, garantizaba a los niños vacunados la seguridad.

Aunque era sin duda un sofisma, el accidente en los Laboratorios Cutter se utilizó como una muy eficaz arma retórica para crear la ilusión de que ambas vacunas tenían riesgos similares de seguridad. Este criterio, así, fue postergado a un segundo lugar, y mañosamente los indudables beneficios prácticos de la vacuna Sabin se colocaron en posición prioritaria. En esta batalla de egos y de posiciones de poder, los niños vulnerables a la poliomielitis quedaron en un segundo plano.

Y después Salk quedó marginado del mundo de la medicina, especialmente de la pediatría y de la salud pública. Con el paso de los años, su prestigio y memoria fueron reivindicados y se le dedicó una de las más importantes y prestigiadas instituciones en donde se desarrollaría, y hasta la fecha se practica a nivel de excelencia, la biología molecular (y también otras disciplinas de frontera, como las neurociencias): el Instituto Salk en La Jolla, California.

Como una de las ironías de la vida, recientemente la Organización Mundial de la Salud jdecidió cambiar la vacuna Sabin por la de Salk!, en los esfuerzos que hoy se llevan a cabo para erradicar por completo la poliomielitis de nuestro planeta ${ }^{21}$.

\section{Los mexicanos estaban listos... y lo lograron}

Cuatro o cinco semanas después del anuncio de Francis sobre la efectividad y la inocuidad de la vacuna Salk, LGV partió rumbo a los EE.UU., en donde, acompañado de algunos de sus colaboradores, conversó muchas horas y días con Jonas Salk y su equipo, y también visitó a Sabin en Cincinnati. En la División de Investigación Biológica estaban puestas sólidas bases, los científicos se habían preparado y capacitado sólidamente, y todo esto, aunado a la generosidad del Dr. Salk, hizo que este breve viaje resultase un éxito, ya que al regresar a México todos, desde el director hasta el más humilde trabajador, se dieron febrilmente a la tarea que un par de años antes se hubiese antojado utópica: fabricar en México, con recursos exclusivamente mexicanos, la vacuna contra la poliomielitis, la cual empezó a aplicarse en nuestro país en abril de $1956^{3,22}$. Es de justicia señalar que, aunado a estos esfuerzos institucionales, se pusieron en marcha los vínculos que LGV había estado cultivando desde tiempo antes con algunas de las industrias farmacéuticas del país: Ios Laboratorios del Dr. Francisco Zapata Castañeda, el Ing. José Ignacio Bolívar y el Sr. Enrique Chávez Peón Hoffman, director de la filial de los Laboratorios Lederle en México, que participaron en la producción de la vacuna. El 15 de noviembre de 1955, el Secretario de Salubridad y Asistencia Dr. Ignacio Morones Prieto, ante el Presidente de la República, Adolfo Ruiz Cortínez, firmó el acta que constituyó el Instituto Nacional de Bienestar de la Niñez, con objeto de reunir y administrar fondos gubernamentales y privados para prevenir enfermedades en niños, en particular la poliomielitis $^{23}$. Con estos cuantiosos donativos, el país pudo producir la vacuna Salk. Se hicieron las adquisiciones finales necesarias, se contrató a los técnicos que todavía hacían falta, se empezaron a importar desde la India monos Rhesus, y habiendo sometido los primeros lotes de la vacuna Salk elaborada íntegramente en México a las pruebas de seguridad y efectividad necesarias, se pasó en 1956 a su producción y a la vacunación en masa (Figs. 2 y 3). Con ello, la frecuencia 


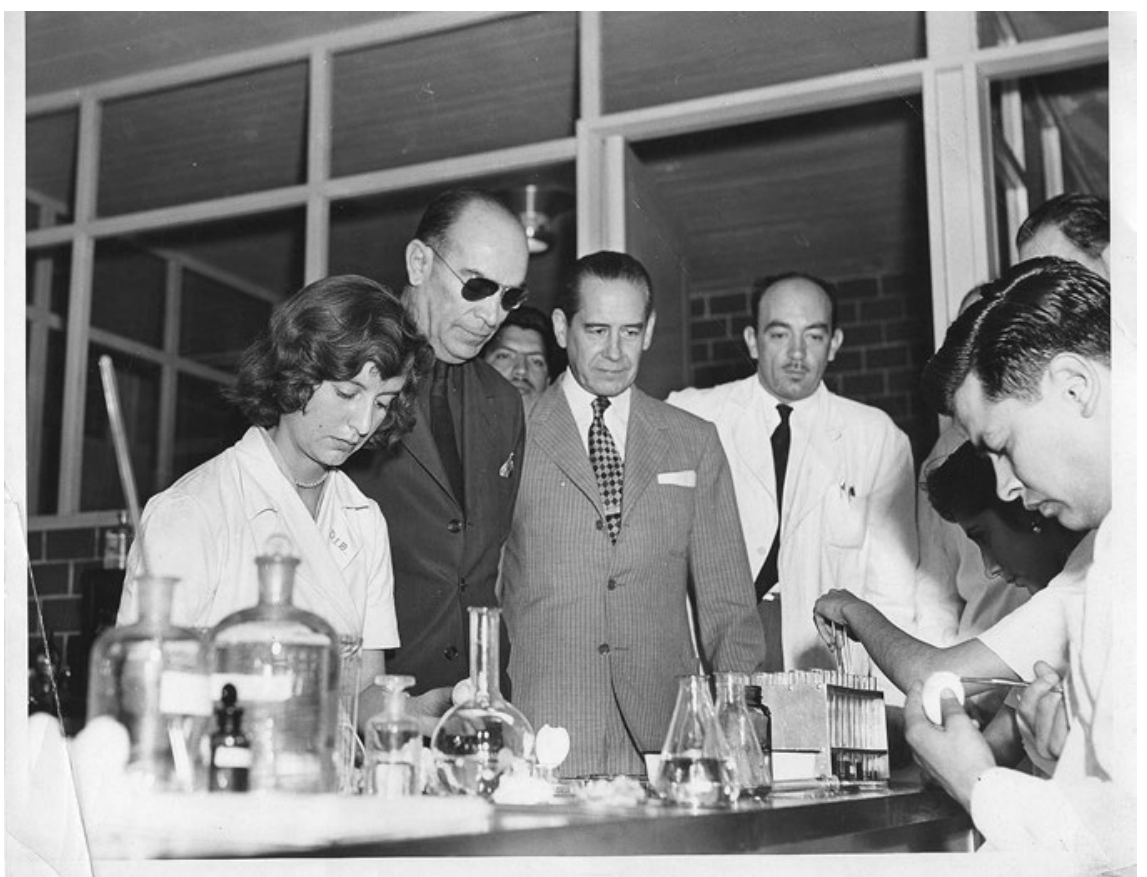

Figura 2. En la División de Investigación Biológica, Beatriz Ordóñez, el secretario de Salubridad y Asistencia lgnacio Morones Prieto, Luis Gutiérrez Villegas, José Laguna y Enrique Cifuentes.

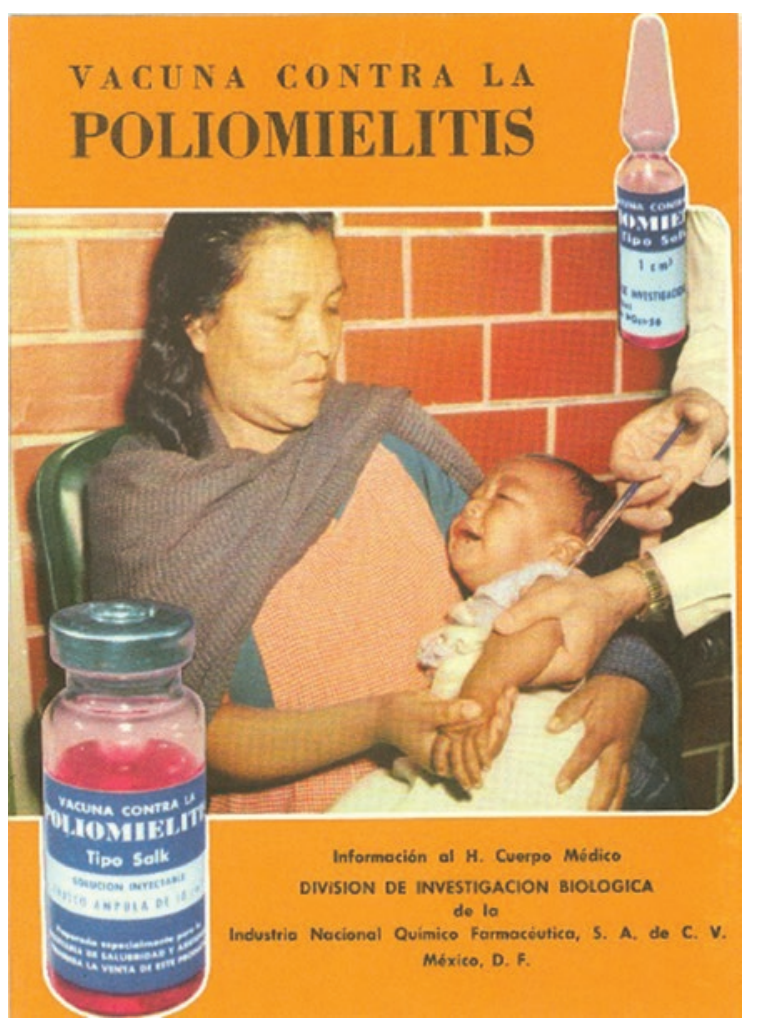

Figura 3. Portada del folleto sobre la vacuna contra la poliomielitis que se repartió ampliamente en México.

de la poliomielitis en México empezó a decaer rápidamente. Como ya se mencionó antes, solo Canadá pudo manufacturar su vacuna antes que México.

\section{La rivalidad entre Salk y Sabin se traslada a México}

LGV era plenamente consciente de las ventajas y las desventajas de los dos tipos de vacuna. Consideró que había que esperar prudentemente por algún tiempo los resultados de los estudios de seguridad de la vacuna Sabin. Él mismo había conseguido una beca a un joven y prometedor microbiólogo, Manuel Ramos Álvarez, para que realizase estudios de posgrado en el laboratorio de Sabin en Cincinnati. En México, el Dr. Federico Gómez, director-fundador del Hospital Infantil de México, tomó el partido de Sabin. Gómez era el líder de la pediatría mexicana, mientras que LGV era un investigador de laboratorio (como ya se mencionó, había colaborado con Gómez estableciendo los laboratorios para diagnóstico cuando se fundó el Hospital Infantil de México). Se dio así en nuestro país una pugna que, en algunos aspectos, fue reflejo de la que sucedía en los EE.UU. entre los doctores Salk y Sabin. Manuel Ramos Álvarez, el becario mexicano en el laboratorio de Sabin, quien compartía muchos de los rasgos de personalidad de su maestro, y no estaba dispuesto a que sus colegas que se habían quedado en México y que estaban produciendo la vacuna Salk se quedaran con la gloria de este logro, fue contratado por el Dr. Gómez en el Hospital Infantil e inició esfuerzos para elaborar la vacuna Sabin. 
A partir de 1963, contando con los resultados de estudios en países como Singapur, Checoslovaquia, la URSS y el propio México, que mostraban la inocuidad de la vacuna Sabin, esta se ha venido aplicando a todos los niños mexicanos ${ }^{24}$. Pero en 2014, la Organización Mundial de la Salud, ante la casi completa erradicación mundial de la enfermedad y dados los riesgos de nuevos brotes derivados de la vacuna con virus vivo atenuado (la de Sabin), recomendó a todos los países que usaran al menos una dosis de la vacuna Salk con virus inactivado en sus campañas sistemáticas de vacunación, a más tardar al final de 2015²1.

\section{Epílogo}

A LGV nunca le interesó el poder por el poder mismo, ni lo deslumbró la fama. Había aceptado, prácticamente a fuerzas, la dirección del Instituto Behring, la que siempre vio como un reto para pagar en parte la deuda que sentía hacia lo mucho que la vida y su país le habían dado.

Ante un conflicto que iba en aumento decidió, parafraseando aquel discurso memorable del Jubileo Profesional de su gran amigo Ignacio Chávez, «levantar sus tiendas, reunir sus bienes y marcharse a otro sitio". Renunció a la dirección de la DIB, que había fundado, y regresó a su hogar y a su laboratorio. Falleció en 1990.

A finales de los años 1950, el gobierno mexicano decidió regresar a Alemania los laboratorios farmacéuticos y químicos que le había incautado cuando los dos países entraron en conflicto durante la Segunda Guerra Mundial, para de esta y otras formas iniciar una nueva etapa de relaciones entre dos pueblos a los que siempre han ligado lazos de respeto y afecto (recuérdese a Alexander von Humboldt).

\section{Agradecimientos}

Los Dres. Silvestre Frenk, Victoria Chagoya, Raúl Ondarza y muy especialmente, con concienzuda, minuciosa y enorme paciencia, la Dra. Ana Cecilia Rodríguez de Romo, leyeron críticamente el manuscrito e hicieron muy valiosas recomendaciones.
El autor escribió el manuscrito siendo recipiente de donativos de la Dirección General de Asuntos del Personal Académico de la Universidad Nacional Autónoma de México (PAPIIT IN208214) y del Consejo Nacional de Ciencia y Tecnología (Fondo SEP-CONACYT 166857).

\section{Bibliografía}

1. Oshinsky DM. Polio. An American story. Oxford: Oxford University Press; 2005. 342 p.

2. Paul JR. A history of poliomyelitis. New Haven: Yale University Press; 1971. 486 p.

3. Gutiérrez-Villegas L. Resultado de la vacuna contra la poliomielitis, tipo Salk, elaborada en México. Gac Med Mex. 1958;88:319-31.

4. Aguilarpico R. El Hospital Infantil de México. Gac Med Mex. 1963;93:1155-64.

5. Coqui C. El centenario de la Academia Nacional de Medicina. Un justo recuerdo. Gac Med Mex. 1964;94:303-4.

6. Gutiérrez-Villegas L. Symposium de virología. Introducción. Gac Med Mex. 1955;85:231-3.

7. Anónimo. La historia de la Industria Nacional Químico Farmacéutica México: QuimiNet; 2011. Disponible en: http://www.quiminet.com/articulos/la-historia-de-la-industria-nacional-quimico-farmaceutica-1949-2576101.htm

8. Gutiérrez Villegas L, Laguna J, Campillo C, et al. Estudios sobre la immunización pasiva contra la poliomielitis con globulinas homólogas. Gac Med Mex. 1952;82:423-36.

9. Gutiérrez Villegas L. Inmunología y epidemiología de las virosis. Gac Med Mex. 1955;85:243-64.

10. Judson HF. The eighth day of creation: makers of the revolution in biology. Expanded ed. Plainview, N.Y.: CSHL Press; 1996. 714 p.

11. Bodian D. Differentiation of types of poliomyelitis viruses; reinfection experiments in monkeys (second attacks). Am J Hyg. 1949;49:200-23.

12. Enders JF, Weller TH, Robbins FC. Cultivation of the Lansing strain of poliomyelitis virus in cultures of various human embryonic tissues. Science. 1949;109:85-7.

13. Salk JE. Studies in human subjects on active immunization against poliomyelitis. I. A preliminary report of experiments in progress. J Am Med Assoc. 1953;151:1081-98.

14. Avery OT, Macleod CM, McCarty M. Studies on the chemical nature of the substance inducing transformation of pneumococcal types: induction of transformation by a desoxyribonucleic acid fraction isolated from pneumococcus type lii. J Exp Med. 1944;79:137-58.

15. Sabin AB. Present status and future possibilities of a vaccine for the control of poliomyelitis. AMA Am J Dis Child. 1953;86:301-10.

16. Broad WJ, Wade N. Betrayers of the truth. New York: Simon and Schuster; 1983. 256 p.

17. Salk JE. Vaccination against paralytic poliomyelitis performance and prospects. Am J Public Health Nations Health. 1955;45(5 Pt 1):575-96.

18. Francis T, Jr., Korns RF, Voight RB, et al. An evaluation of the 1954 poliomyelitis vaccine trials. Am J Public Health Nations Health. 1955;45(5 Pt 2):1-63.

19. Sabin AB. Oral poliovirus vaccine. History of its development and prospects for eradication of poliomyelitis. JAMA. 1965;194:872-6.

20. Offit PA. The Cutter incident, 50 years later. $\mathrm{N}$ Engl J Med. 2005;352:1411-2.

21. Roberts L. Polio eradication. Rethinking the polio endgame. Science. 2009;323:705.

22. Rodríguez Pérez ME. El Consejo de Salubridad General y las epidemias. México, D.F.: Secretaría de Salud, p. 167.

23. Anónimo. Instituto Nacional de Bienestar de la Niñez. El Universal. 1955, 16 de noviembre; Sect. Primera sección.

24. Wehrle PF, Leedom JM, Portnoy B, et al. Safety of Sabin oral poliovaccine strains; mass immunization program in Los Angeles County, 19621963. JAMA. 1963;186:821-6. 